\title{
AN EVALUATION MODEL OF BUSINESS INTELLIGENCE FOR ENTERPRISE SYSTEMS WITH NEW EXTENSION OF CODAS (CODAS-IVIF)
}

\author{
Jalil Heidary Dahooei, Edmundas Kazimieras Zavadskas, \\ Amir Salar Vanaki, Hamid Reza Firoozfar, \\ Mehdi Keshavarz-Ghorabaee
}

\section{Introduction}

Nowadays, organizations may deal with a variety of issues challenging the decision making such as overflow of data, lack of information, lack of knowledge and insufficiency of reports (Lin, Tsai, Shiang, Kuo, \& Tsai, 2009). Over the years, management information systems including DSS, ES, EIS, and so on have been widely supported companies with their decisions; however, a key missing capability to manage decisions for emergencies, monitoring competition, collect data from different points of views, and carrying out constant analyses of numerous data and consider different variants of organization performance, is the major cause of failure to adequately meet the needs of enterprise decision-makers (Olszak \& Ziemba, 2007). Given the widespread changes and the dynamics of today's environment, organizations need to use new information systems that can analyse the various causal relationships both within and outside the organization. Hence they move towards using business intelligence (Gangadharan \& Swami, 2004; Duan \& Da Xu, 2012).

The term "Business Intelligence (BI)" refers to a set of methods, processes, architectures and technologies that converts a set of data into meaningful and usable information in order to meet the needs of the organization (Chang, 2014). Today, business intelligence has become one of the most important priorities of some organizations and has been widely considered (Işık, Jones, \& Sidorova, 2013). By using various technological components such as databases, visualization tools and OLAP, BI systems allow decision makers to work with several sets of data and help them in decision making process
(Chen, Chiang, \& Storey, 2012; Holsapple, Lee-Post, \& Pakath, 2014). BI can aggregate, integrate, and analyse the data in separate databases (such as CRM, SCM, ERP, and other enterprise systems) to help the organization predict the behaviour of competitors, suppliers, customers, technological changes, products, and different services with reasonable certainty (Yeoh \& Koronios, 2010; Ghazanfari, Jafari, \& Rouhani, 2011). Previously, decision support systems were separate systems that could be called island systems because of poor communication with other systems. But today, enterprise systems form a basis for the organization and experts have developed a comprehensive decision support environment for management with the use of business intelligence (Alter, 2004).

In recent years, there has been great interest in $\mathrm{BI}$ as a vital program that aims to create decision-support environment for management, ensure adequate insight into organizational processes, strategies and operations, and improve organization performance and competitiveness (Lönnqvist \& Pirttimäki, 2006; Duan \& Da Xu, 2012). The growing tendency to use smart devices in enterprise systems has increased the practical necessity for the $\mathrm{BI}$ evaluation of enterprise systems (Rouhani, Ghazanfari, \& Jafari, 2012). An assessment of the efficiency and performance of information systems is a key element for a successful implementation (Lin, Tsai, Shiang, Kuo, \& Tsai, 2009). It is, therefore, of great interest to assess the levels of business intelligence as a measure of organizational success in responding to the needs of users. 
Despite the importance of this field, there has been a little research on the evaluation business intelligence of enterprise systems (Lin, Tsai, Shiang, Kuo, \& Tsai, 2009). Moreover, the majority of studies consider business intelligence as tools or separated systems to enterprise systems. Therefore, it seems critical to develop an assessment model of business intelligence for enterprise systems. The need for measuring all the pros and cons of $\mathrm{BI}$, as well as the presence of multiple factors considered both by users and experts in the field has changed the business evaluation into a multiple attribute decision making problem (Lin, Tsai, Shiang, Kuo, \& Tsai, 2009).

(Rouhani, Ghazanfari, \& Jafari, 2012) was one of the few studies in assessing business intelligence for enterprise systems using a fuzzy approach based on experts' opinion. However, due to the fact that human assessments are always associated with uncertainty, using approaches such as IVIF approach is recommended to increase the accuracy of the evaluation (Garg, 2017). For this reason, the current study seeks to develop a modern evaluation approach of business intelligence for enterprise systems by using new multiple attribute decisionmaking (MADM) technique. To this end, an extension of CODAS (Combinative Distancebased Assessment) method with IntervalValued Intuitionistic Fuzzy Sets (IVIF) is designed and the CODAS-IVIF procedure is provided. As one of the recent MADM methods, the CODAS approach was developed by (Kershavarz Ghorabaee, Zavadskas, Turskis, \& Antucheviciene, 2016). In this method, the utility of alternatives is determined based on the Euclidean distance, while the Taxicab distance is calculated by the negative-ideal solution. And, this procedure shows significant performance than other distance-based methods like TOPSIS and VIKOR, as a combination of two distances is applied in the assessment process of alternatives (Kershavarz Ghorabaee, Amiri, Zavadskas, Hooshmand, \& Antuchevičienè, 2017). In relation to WASPAS, COPRAS, TOPSIS, VIKOR and EDAS, the results of comparative assessments and sensitivity analysis confirm the validity of the proposed CODAS method (Kershavarz Ghorabaee, Zavadskas, Turskis, \& Antucheviciene, 2016). Further, Kershavarz Ghorabaee et al. (2017) provided a fuzzy extension of CODAS
(Kershavarz Ghorabaee, Amiri, Zavadskas, Hooshmand, \& Antuchevičienè, 2017). As stated above, we here explore the integrated model of fuzzy CODAS and an interval-valued intuitionistic fuzzy set that leads to more efficient and effective decision making method for conditions of uncertainty.

In the following section, the study will first explore the literature for research papers evaluating business intelligence. As decision criteria and alternatives defined, the methodology will provide major research methods and tools. Here, the CODAS method is extended using the intuitionistic fuzzy logic with interval values. In the results and discussion section provides an expert analysis for a set of five enterprise systems by the proposed CODAS-IVIF approach. Finally, the "Conclusion and Recommendations" develops the analysis.

\section{Literature Review}

As stated before, the concept of $\mathrm{BI}$ has recently received a remarkable amount of academic interest due to major needs of organizations to make sound decisions and appropriate use of information. Differences in views and attitudes towards this concept have led to a wide variety of definitions in the literature. $\mathrm{BI}$ is an umbrella concept, covering a broad set of function, developed by Dresner in 1989 as a set of concepts and methods to improve decision-makings in organizations by using computer-based support systems (Sangari \& Razmi, 2015). BI refers to technologies, applications, concepts and techniques used for the collection, integration, and demonstration of business information in order to make better decisions (Massa \& Testa, 2005). Many components form a typical BI application, like as which are data warehouse, data mining, ETL, analytical tools, data visualization and analysis, score board, dashboard, OLAP and etc. (Aruldoss, Lakshmi Travis, \& Prasanna Venkatesan, 2014). In general, the purpose of $\mathrm{BI}$ is to help organizations to improve timeliness and quality of inputs to the decision making process (Rubin \& Rubin, 2013). Based on a brief review of the available literature, the enterprise intelligence can be classified in three approaches, namely; managerial, technical, and system-enabler (Ghazanfari, Jafari, \& Rouhani, 2011). The managerial approach defines $\mathrm{BI}$ as a process in which data collected from internal and external sources are integrated in order to 
generate information relevant to the decisionmaking process. It has also been reported in several studies (Power, 2008; Bose, 2009). However, the technical approach considers BI as a set of tools, algorithms and technologies that support the above-mentioned process and its implementation. Further, the third approach proposed in the empowerment of enterprise systems; focuses on the characteristics of $\mathrm{BI}$ as effective factors that may increase its information processing capabilities (Ghazanfari, Jafari, \& Rouhani, 2011).

In addition to broad research at $\mathrm{BI}$, some efforts have been made to deal with the business intelligence performance assessment. The success of any $\mathrm{BI}$ system depends on information access quality and information content quality (Popovič, Hackney, Coelho, \& Jaklič, 2012). The accuracy of content, flexibility, ease of operation, on-time response, consistency and integration of the output, its reliability, and system security are the most common criteria for the evaluation of information systems (Doll \& Torzadeh, 1988; Tan \& Lo, 1990). Using MADM techniques and network analysis, (Lin, Tsai, Shiang, Kuo, \& Tsai, 2009) developed a performance assessment model for $\mathrm{BI}$ systems. The authors showed the necessity of measurement of $\mathrm{BI}$ effectiveness, and determined a set of nine critical factors, including response time of system, its security, accuracy of the output, implementing the consultants' recommendations, support from top management and users, its conformity to requirements, its support of organizational efficiency, and support of decision-makings in the organization. (Ghazanfari, Jafari, \& Rouhani, 2011) designed an assessment tool of $\mathrm{BI}$ for enterprise systems, regarding the considerable value of $\mathrm{BI}$ in empowering organizational systems. Through a comprehensive review on the literature, the authors identified 34 criteria in evaluating the enterprise-level $\mathrm{BI}$, presented in the table below. Also, (Rouhani, Ghazanfari, \& Jafari, 2012) proposed a new assessment model of $\mathrm{BI}$ for enterprise systems using fuzzy TOPSIS method. (Yan, Wang, \& Liu, 2012) used AHP and fuzzy TOPSIS to evaluate BI systems based on four criteria set including System construction operation and

\section{Tab. 1: Evaluation criteria of BI for enterprise systems}

\begin{tabular}{l|l|l|l} 
Code & \multicolumn{1}{|c|}{ Criterion Title } & Code & \multicolumn{1}{c}{ Criterion Title } \\
\hline C1 & $\begin{array}{l}\text { Group sorting tools and methodology } \\
\text { (Groupware) }\end{array}$ & C18 & Alarms and warnings \\
\hline C2 & Group decision-making tools & C19 & Dashboard/recommender \\
\hline C3 & Flexible models & C20 & Combination of experiments \\
\hline C4 & Problem clustering & C21 & Situation awareness modelling \\
\hline C5 & Optimization technique & C22 & Environmental awareness \\
\hline C6 & Learning technique & C23 & Fuzzy decision-making \\
\hline C7 & Import data from other systems & C24 & OLAP \\
\hline C8 & Export reports to other systems & C25 & Data mining techniques \\
\hline C9 & Simulation models & C26 & Data warehouses \\
\hline C10 & Risk simulation & C27 & Web channel \\
\hline C11 & Financial analyses tools & C28 & Mobile channel \\
\hline C12 & Visual graphs & C29 & E-mail channel \\
\hline C13 & Summarization & C30 & Intelligent agent \\
\hline C14 & Evolutionary prototyping model & C31 & Multi-agent \\
\hline C15 & Dynamic model prototyping & C32 & MCDM tools \\
\hline C16 & Backward and forward reasoning & C33 & Stakeholders' satisfaction \\
\hline C17 & Knowledge reasoning & C34 & Reliability and accuracy of analysis \\
\hline & & &
\end{tabular}

Source: Ghazanfari, Jafari, and Rouhani (2011) 


\section{Informační management}

maintenance, System user satisfaction, Internal influences and external influences. Because of the comprehensiveness of the criteria defined by (Ghazanfari, Jafari, \& Rouhani, 2011), these criteria are derived and used to achieve the purpose of this study. Tab. 1 shows the criteria.

\section{Methodology}

The purpose of this study is to propose a new model to evaluate the level of $\mathrm{BI}$ for enterprise systems. To this end, the current study presents an extension of the CODAS method - a new multi-criteria decision-making approach based on the intuitionistic fuzzy logic with interval values. Also, through a review on the literature, 34 criteria are provided for the evaluation of business intelligence. Given the variety of criteria, the weighting process was employed by using the linguistic variables and expert panels. Further, a number of five expert systems were defined by the expert opinions, and examined through an interval-valued intuitive fuzzy CODAS method. Fig. 1 shows the research process.

\section{Fig. 1: Research methodology}

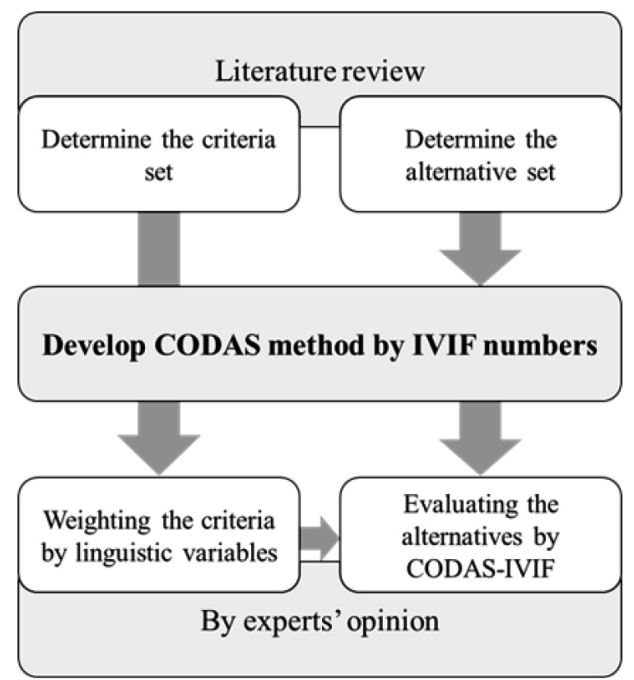

Source: own

\subsection{Interval-Valued Intuitionistic Fuzzy Sets}

The notion of interval-valued intuitionistic fuzzy (IVIF) sets was first introduced by Atanassov and Gargov as follows (Atanassov \& Gargov, 1989).

Definition 1 - An Interval intuitionistic fuzzy set (IIFS) is defined in a set $X$ as Equation (1).

$$
A=\left\{\left\langle x, \tilde{t}_{A}(x), \tilde{f}_{A}(x)\right\rangle \mid x \in X\right\}
$$

where, $\tilde{t}_{A}(x)$ and $\tilde{f}_{A}(x)$ are two functions with the value range of $[0,1]$, indicating the degrees of membership and non-membership, respectively. Note that the sum of the maximum values of these two is also in the interval $[0,1]$ (Xu, 2007).

Definition 2 - If $\widetilde{\alpha}_{1}=\left(\left[a_{1}, b_{1}\right],\left[c_{1}, d_{1}\right]\right)$ and $\widetilde{\alpha}_{2}=\left(\left[a_{2}, b_{2}\right],\left[c_{2}, d_{2}\right]\right)$ are two IVIF numbers, then some operating rules based on IVIF logic are described as Equations (2)-(5) (Liu, Lin, Wen, \& Ledwich, 2012). 


$$
\begin{aligned}
& \tilde{\alpha}_{1} \oplus \tilde{\alpha}_{2}=\left(\left[a_{1}+a_{2}-a_{1} a_{2}, b_{1}+\right.\right. \\
& \left.\left.+b_{2}-b_{1} b_{2}\right],\left[c_{1} c_{2}, d_{1} d_{2}\right]\right) \\
& \tilde{\alpha}_{1} \otimes \tilde{\alpha}_{2}=\left(\left[a_{1} a_{2}, b_{1} b_{2}\right],\left[c_{1}+c_{2}-\right.\right. \\
& \left.\left.-c_{1} c_{2}, d_{1}+d_{2}-d_{1} d_{2}\right]\right) \\
& \lambda \tilde{\alpha}_{1}=\left(\left[1-\left(1-a_{1}\right)^{\lambda}, 1-\left(1-b_{1}\right)^{\lambda}\right],\right. \\
& \left.\left[c_{1}^{\lambda}, d_{1}^{\lambda}\right]\right), \quad \lambda>0 \\
& \tilde{\alpha}_{1}^{\lambda}=\left(\left[a_{1}^{\lambda}, b_{1}^{\lambda}\right],\left[1-\left(1-c_{1}\right)^{\lambda},\right.\right. \\
& \left.\left.1-\left(1-d_{1}\right)^{\lambda}\right]\right), \quad \lambda>0
\end{aligned}
$$

Definition 3 - Suppose that $\widetilde{\alpha}=([a, b],[c, d])$ is an IVIF number. For $\widetilde{\alpha}$, the score function
$S(\widetilde{\alpha})$, accuracy function $H(\widetilde{\alpha})$, membership uncertainty index $T(\widetilde{\alpha})$, and hesitation uncertainty index $G(\widetilde{\alpha})$ can be defined as Equations (6)-(9) (Wang \& Liu, 2013).

$$
\begin{aligned}
& S(\tilde{\alpha})=\frac{a+b-c-d}{2} \\
& H(\tilde{\alpha})=\frac{a+b+c+d}{2} \\
& T(\tilde{\alpha})=b+c-a-d \\
& G(\tilde{\alpha})=b+d-a-c
\end{aligned}
$$

According to the indices, operating rules and definitions above mentioned, these numbers are now ranked as in Fig. 2 (Wang \& Liu, 2013).

\section{Fig. 2: Ranking Rules for IVIF Number}

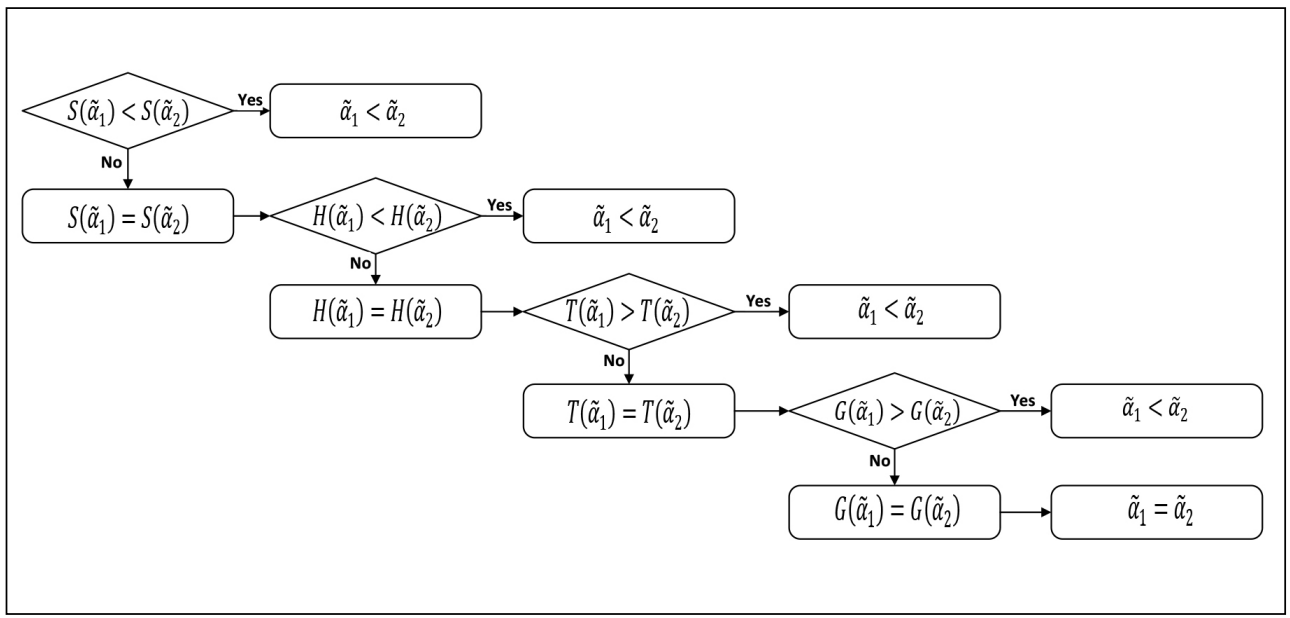

Source: Wang and Liu (2013)

Definition 4- If $\widetilde{A}_{1}=\left[\left(\left[a_{i}^{(1)}, b_{i}^{(1)}\right], c_{i}^{(1)}, d_{i}^{(1)}\right)\right]_{1 \times n}$ and $\widetilde{A}_{2}=\left[\left(\left[a_{i}^{(2)}, b_{i}^{(2)}\right], c_{i}^{(2)}, d_{i}^{(2)}\right)\right]_{1 \times n}$ are two IVIF numbers, then the distance between the numbers $\widetilde{A}_{1}$ and $\widetilde{A}_{2}$ is defined as follows - see Eq. 10 (Xue, You, Lai, \& Liu, 2016).

$$
\begin{aligned}
& D\left(\tilde{A}_{1}, \tilde{A}_{2}\right)=\left[\frac{1}{4 n} \sum_{i=1}^{n}\left(\left(\left|a_{i}^{(1)}-a_{i}^{(2)}\right|\right)^{\lambda}+\left(\left|b_{i}^{(1)}-b_{i}^{(2)}\right|\right)^{\lambda}+\left(\left|b_{i}^{(1)}-b_{i}^{(2)}\right|\right)^{\lambda}+\left(\left|b_{i}^{(1)}-b_{i}^{(2)}\right|\right)^{\lambda}\right)\right]^{\frac{1}{\lambda}}, \lambda>0 \\
& D_{H}\left(\tilde{A}_{1}, \tilde{A}_{2}\right)=\frac{1}{4 n} \sum_{i=1}^{n}\left(\left|a_{i}^{(1)}-a_{i}^{(2)}\right|+\left|b_{i}^{(1)}-b_{i}^{(2)}\right|+\left|c_{i}^{(1)}-c_{i}^{(2)}\right|+\left|d_{i}^{(1)}-d_{i}^{(2)}\right|\right)
\end{aligned}
$$


Further, if $\lambda=2$, equation (10) defines the Euclidean distance as follows.

$$
\begin{aligned}
& D_{E}\left(\tilde{A}_{1}, \tilde{A}_{2}\right)=\sqrt{\frac{1}{4 n} \sum_{i=1}^{n}\left(\left(a_{i}^{(1)}-a_{i}^{(2)}\right)^{2}+\left(b_{i}^{(1)}-b_{i}^{(2)}\right)^{2}+\right.} \\
& \left.+\left(c_{i}^{(1)}-c_{i}^{(2)}\right)^{2}+\left(d_{i}^{(1)}-d_{i}^{(2)}\right)^{2}\right), \lambda>0
\end{aligned}
$$

Definition 5 - When $x_{i j}=\left[\left(l_{i j}, l_{i j}^{\prime}\right),\left(u_{i j}^{\prime}, u_{i j}\right)\right]$ represents the elements of the decision matrix as the IVIF numbers, then the maximum and minimum values of fuzzy numbers are computed by using Equations (13) and (14) (Boran, Genç, Kurt, \& Akay, 2009; Zavadskas, Antucheviciene, Hajiagha, \& Hashemi, 2014).

$$
\begin{aligned}
\max _{i} x_{i j} & =\left[\left(\max _{i} l_{i j}, \max _{i} l_{i j}^{\prime}\right),\left(\min _{i} u_{i j}^{\prime}, \min _{i} u_{i j}\right)\right] \\
\min _{i} x_{i j} & =\left[\left(\min _{i} l_{i j}, \min _{i} l_{i j}^{\prime}\right),\left(\max _{i} u_{i j}^{\prime}, \max _{i} u_{i j}\right)\right]
\end{aligned}
$$

Definition 6 - If $\tilde{\alpha}_{1}=\left(\left[a_{1}, b_{1}\right],\left[c_{1}, d_{1}\right]\right)$ and $\widetilde{\alpha}_{2}=\left(\left[a_{2}, b_{2}\right],\left[c_{2}, d_{2}\right]\right)$ are two IVIF numbers, then the division relation can be calculated as follow (Liu, 2010).

$$
\begin{aligned}
& \frac{\tilde{A}_{1}}{\tilde{A}_{2}}=\left(\left[\min \left(a_{1}, a_{2}\right), \min \left(b_{1}, b_{2}\right)\right],\right. \\
& \left.\left[\max \left(c_{1}, c_{2}\right), \max \left(d_{1}, d_{2}\right)\right]\right)
\end{aligned}
$$

\subsection{CODAS Method}

As stated before, the CODAS method is a new efficient MCDM method, developed by Kershavarz Ghorabaee et al. in 2016 (Kershavarz Ghorabaee, Zavadskas, Turskis, \& Antucheviciene, 2016). In this procedure, the desirability of all available alternatives is measured on the basis of two criteria, measuring the distance between each alternative and the negative-ideal solution. The first criterion actually calculates the Euclidean distance on $I^{2}$-norm space, whereas the second estimates the Hamming distance on $I^{1}$-norm space (Kershavarz Ghorabaee, Amiri, Zavadskas, Hooshmand, \& Antuchevičienè, 2017). Obviously, one alternative of the greatest distance from the negative-ideal solution will provide the highest desirability. In the CODAS method, when two alternatives have higher similarity in the Euclidean norm, the second criterion - i.e., the Hamming distance - is used as the basis of comparison. The $I^{2}$-norm space is preferred; however, both criteria are utilized for comparing the assessment score of alternatives. Remember that there are $n$ alternatives and $m$ criteria in a decision problem. The steps of the CODAS method for multicriteria decision-making problems are listed below (Kershavarz Ghorabaee, Zavadskas, Turskis, \& Antucheviciene, 2016).

Step 1: Construct decision matrix

First, a decision matrix $X$ is developed by using Equation (16).

$$
X=\left[x_{i j}\right]_{n \times m}=\left[\begin{array}{cccc}
x_{11} & x_{12} & \cdots & x_{1 m} \\
x_{21} & x_{22} & \cdots & x_{2 m} \\
\vdots & \vdots & \vdots & \vdots \\
x_{n 1} & x_{n 2} & \cdots & x_{n m}
\end{array}\right]
$$

where, $x_{i j}\left(x_{i j} \geq 0\right)$ represents the value of $\mathrm{i}_{\mathrm{th}}(i \in\{1,2, \ldots, n\})$ alternative with respect to $\mathrm{j}_{\mathrm{th}}(j \in\{1,2, \ldots, m\})$ criterion.

Step 2: Determine normalized decision matrix

In order to compare different alternatives, it is necessary to normalize the decision matrix values. Here, a linear normalization method is used to obtain normalized values based on Equation (17).

$$
n_{i j}= \begin{cases}\frac{x_{i j}}{\max _{i} x_{i j}} & \text { if } j \in N_{b} \\ \frac{\min _{i} x_{i j}}{x_{i j}} & \text { if } j \in N_{c}\end{cases}
$$

where, $N_{b}$ and $N_{c}$ denotes the set of positive and negative criteria.

Step 3: Calculate weighted normalized decision matrix

To this end, the weighted normalized values can be obtained by using the following relation. Where, $w_{j}$ shows the weight of $j_{\text {th }}$ criterion, and two conditions $\sum_{j=I}^{n} w_{j}=1$ and $\left(0<w_{j}<1\right)$ hold.

$$
r_{i j}=w_{j} n_{i j}
$$

Step 4: Determine negative-ideal solution

As to compute the distance between each alternative from the negative-ideal solution, it is necessary first to determine the negative-ideal solution by using the following equations.

$$
\begin{aligned}
& n s=\left[n s_{j}\right]_{1 \times m} \\
& n s_{j}=\min _{i} r_{i j}
\end{aligned}
$$


Step 5: Calculate distance of alternatives from negative-ideal solution

The Euclidean and Hamming distances of each alternative from a negative-ideal solution are calculated by using Equations (21) and (22).

$$
\begin{aligned}
& E_{i}=\sqrt{\sum_{j=1}^{m}\left(r_{i j}-n s_{j}\right)^{2}} \\
& T_{i}=\sum_{j=1}^{m}\left|r_{i j}-n s_{j}\right|
\end{aligned}
$$

Step 6: Determine relative assessment matrix

A relative assessment matrix can be defined as follows.

$$
\begin{aligned}
& R a=\left[h_{i k}\right]_{n \times n} \\
& h_{i k}=\left(E_{i}-E_{k}\right)+\left(\psi\left(E_{i}-E_{k}\right) \times\right. \\
& \left.\times\left(T_{i}-T_{k}\right)\right)
\end{aligned}
$$

where, $k \in\{1,2, \ldots, n\}$ and $\psi$ denote the threshold function which determines an equal Euclidean distance between two alternatives. This function can be defined as follows.

$$
\psi(x)= \begin{cases}1 & \text { if }|x| \geq \tau \\ 0 & \text { if }|x|<\tau\end{cases}
$$

The threshold parameter $(\tau)$ of this function can be determined by decision-makers. In this study, the values between 0.01-0.05 are used for the calculations.

If the difference space between two alternatives for the Euclidean distance is less than $\mathrm{T}$, then two alternatives are compared using the Taxicab distance. Here, we use $\mathrm{T}=0.02$ for the calculations.

Step 7: Calculate assessment score for alternatives

The assessment score is used for comparison and ranking processes of all available alternatives, using Equation (26).

$$
H_{i}=\sum_{k=1}^{n} h_{i k}
$$

\section{Step 8: Rank alternatives}

Now, the alternatives are ranked according to the decreasing values of assessment scores.

\subsection{Extended CODAS-IVIF Method}

Fig. 3 shows the steps of proposed CODAS-IVIF method for the evaluation of MADM problems.

Step 1: Construct interval-valued fuzzy decision matrix

If $\hat{X}=\left[\hat{x}_{i j}\right]$ denoted the decision matrix reflecting experts' preferences, then $\hat{x}_{i j}$ is represented as follows (Eq. 27).

Step 2: Determined interval-valued normalized fuzzy decision matrix

According to the definitions given in Equations (13)-(15), the interval-valued normalized fuzzy decision matrix is determined by using Equation (28).

$$
\begin{gathered}
\hat{x}_{i j}=\left[\left(\hat{l}_{i j}, \hat{l}_{i j}^{\prime}\right),\left(\hat{u}_{i j}^{\prime}, \hat{u}_{i j}\right)\right] \\
\widehat{X}=\left[\begin{array}{ccccc}
\hat{x}_{01} & \ldots & \hat{x}_{0 j} & \ldots & \hat{x}_{0 n} \\
\vdots & \ddots & \vdots & \ddots & \vdots \\
\hat{x}_{i 1} & \ldots & \hat{x}_{i j} & \ldots & \hat{x}_{i n} \\
\vdots & \ddots & \vdots & \ddots & \vdots \\
\hat{x}_{m 1} & \ldots & \hat{x}_{m j} & \ldots & \hat{x}_{m n}
\end{array}\right] \quad i=\overline{0, m} ; j=\overline{1, n} \\
\hat{n}_{i j}=\left\{\begin{array}{c}
\left(\left[\min \left(\hat{l}_{i j}, \max _{i} \hat{l}_{i j}\right), \min \left(\hat{l}_{i j}^{\prime}, \max _{i} \hat{l}_{i j}^{\prime}\right)\right],\left[\max \left(\hat{u}_{i j}^{\prime}, \min _{i} \hat{u}_{i j}^{\prime}\right), \max \left(\hat{u}_{i j}, \min _{i} \hat{u}_{i j}\right)\right]\right) \text { if } j \in N_{b} \\
\left(\left[\min \left(\hat{l}_{i j}, \min _{i} \hat{l}_{i j}\right), \min \left(\hat{l}_{i j}^{\prime}, \min _{i} \hat{l}_{i j}^{\prime}\right)\right],\left[\max \left(\hat{u}_{i j}^{\prime}, \max _{i} \hat{u}_{i j}^{\prime}\right), \max \left(\hat{u}_{i j}, \max _{i} \hat{u}_{i j}\right)\right]\right) \text { if } j \in N_{c}
\end{array}\right. \\
=\left\{\begin{array}{c}
\left(\left[1-\left(1-\min \left(\hat{l}_{i j}, \max _{i} \hat{l}_{i j}\right)\right)^{w_{j}}, 1-\left(1-\min \left(\hat{l}_{i j}^{\prime}, \max _{i} \hat{l}_{i j}^{\prime}\right)\right)^{w_{j}}\right],\left[\max \left(\hat{u}_{i j}^{\prime}, \min \hat{u}_{i}^{\prime} \hat{u}_{i j}\right)^{w_{j}} \max \left(\hat{u}_{i j}, \min _{i} \hat{u}_{i j}\right)^{w_{j}}\right]\right) \text { if } j \in N_{b} \\
\left(\left[1-\left(1-\min \left(\hat{l}_{i j}, \min _{i} \hat{l}_{i j}\right)\right)^{w_{j}}, 1-\left(1-\min \left(\hat{l}_{i j}^{\prime}, \min _{i} \hat{l}_{i j}^{\prime}\right)\right)^{w_{j}}\right],\left[\max \left(\hat{u}_{i j}^{\prime}, \max _{i} \hat{u}_{i j}^{\prime}\right), \max \left(\hat{u}_{i j}, \max _{i} \hat{u}_{i j}\right)^{w_{j}}\right]\right) \text { if } j \in N_{c}
\end{array}\right. \\
\hat{r}_{i j}=\left(\left[\hat{a}_{i j}^{r}, \hat{b}_{i j}^{r}\right],\left[c_{i j}^{r}, d_{i j}^{r}\right]\right)
\end{gathered}
$$




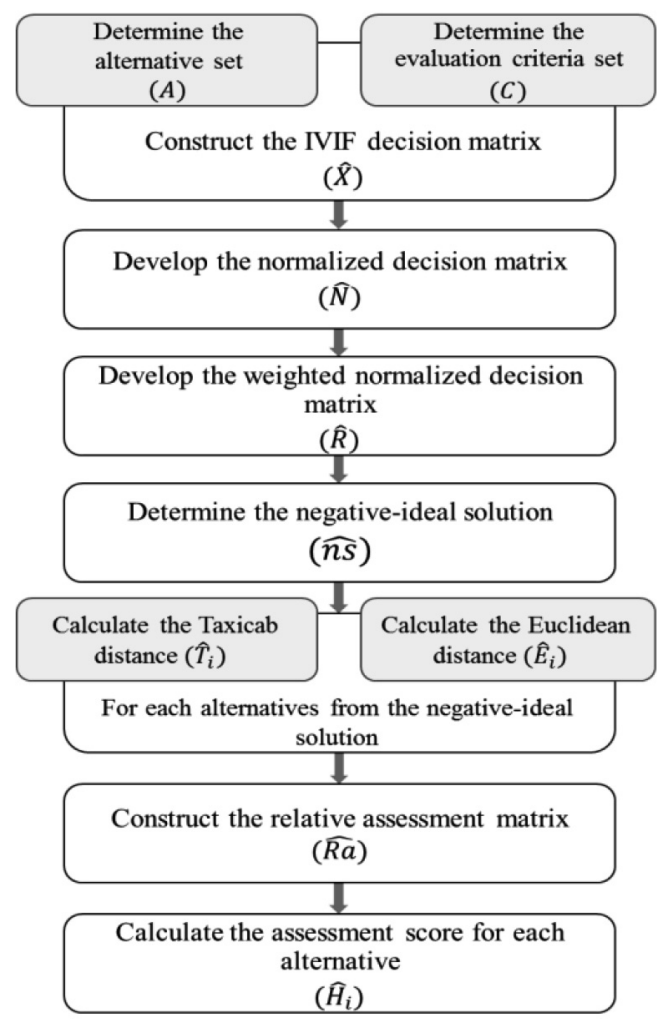

Source: own

$\widehat{n s}=\left[\widehat{n s}_{j}\right]_{1 \times m}$
$\widehat{n S}_{j}=\min _{i} r_{i j}=\left[\left(\min _{i} \hat{a}_{i j}^{r}, \min _{i} \hat{b}_{i j}^{r}\right),\left(\max _{i} \hat{c}_{i j}^{r}, \max _{i} \hat{d}_{i j}^{r}\right)\right]$

$=\sqrt{\frac{1}{4 n} \sum_{i=1}^{n}\left(\left(\hat{a}_{i j}^{r}-\min _{i} \hat{a}_{i j}^{r}\right)^{2}+\left(\hat{r}_{i j}, \widehat{n s}_{j}\right)\right.}$

$\hat{T}_{i}=D_{H}\left(\hat{r}_{i j}, \widehat{n s}_{j}\right)$
$=\frac{1}{4 n} \sum_{i=1}^{n}\left(\left|\hat{a}_{i j}^{r}-\min _{i} \hat{a}_{i j}^{r}\right|+\left|\hat{b}_{i j}^{r}-\min _{i} \hat{b}_{i j}^{r}\right|+\left|\hat{c}_{i j}^{r}-\max _{i} \hat{c}_{i j}^{r}\right|+\left|\hat{d}_{i j}^{r}-\max _{i} \hat{d}_{i j}^{r}\right|\right)$

$\widehat{R a}=\left[\hat{h}_{i k}\right]_{n \times n}$
$\hat{h}_{i k}=\left(\hat{E}_{i}-\hat{E}_{k}\right)+\left(\hat{\psi}\left(\hat{E}_{i}-\hat{E}_{k}\right) \times\left(\hat{T}_{i}-\hat{T}_{k}\right)\right)$ 
Step 3: Calculate weighted normalized decision matrix

Equations (4) and (18) are used to determine the weighted normalized decision matrix. The result is given as follows (Eq. 29).

Step 4: Determine negative-ideal solution

Considering the definitions described in Equations (14), (21) and (22), the negativeideal solution can be calculated by using Equation (30).

Step 5: Calculate Euclidean and Hamming Distances of alternatives from negative-ideal solution

Based on the definitions provided by Equations (23), (24) and (30), the values of Euclidean and Hamming distances of all available alternatives are calculated by the following relations (Eqs. 31-32), respectively.

Step 6: Construct relative assessment matrix

This is shown as follows (Eq. 33), where, $k \in\{1,2, \ldots, n\}$ and $\psi$ denote the threshold function which determines an equal Euclidean distance between two alternatives. This function can be defined as follows.

$$
\widehat{\psi}(x)= \begin{cases}1 & \text { if }|x| \geq \theta \\ 0 & \text { if }|x|<\theta\end{cases}
$$

The threshold parameter $(\theta)$ of this function can be determined by decision-makers. In this study, the values between 0.01-0.05 are suggested for the calculations. Again, if the difference space between two alternatives for the Euclidean distance is less than $\theta$, then two alternatives are compared using the Taxicab distance. Here, we use $\theta=0.02$ for the calculations.

Step 7: Calculate assessment score for alternatives

As stated before, the assessment score can be determined as follows.

$$
\widehat{H}_{i}=\sum_{k=1}^{n} \widehat{h}_{i k}
$$

\section{Step 8: Rank alternatives}

Now, the alternatives are ranked according to the decreasing values of assessment scores.

\section{Research Results}

In order to solve the proposed decision-making problem by using the extended CODAS-IVIF, the decision makers were asked to determine the relative importance of the criteria according to their own opinions. Finally, the weighting values of all available criteria were determined by calculating the average values obtained through the expert panel discussions. As the criteria weights estimated, the expert panel was asked to evaluate a set of five alternatives against the present list of 34 criteria. The linguistic variables for IVIF numbers were also used (Tab. 2). Tab. 3 shows the result from the expert evaluation and the weighting values.

As seen, criteria such as visual graphs, dashboard, data warehouses, meeting stakeholders' satisfaction, and reliability and accuracy of analysis are identified as the most important criteria, according to experts. In this step, the decision matrix is transformed into interval-valued intuitionistic fuzzy numbers according to Tab. 2. In order to

\section{Tab. 2: Linguistic variables corresponding IVF numbers}

\begin{tabular}{l|l|l}
\multicolumn{1}{c|}{ IVIFNs } & \multicolumn{1}{c|}{ Symbol } & \multicolumn{1}{c}{ Linguistic Variable } \\
\hline$([0.9,1.0],[0.0,0.0])$ & VG & Very Good \\
\hline$([0.8,0.8],[0.1,0.1])$ & G & Good \\
\hline$([0.6,0.7],[0.2,0.3])$ & MG & Medium Good \\
\hline$([0.5,0.5],[0.4,0.5])$ & M & Medium \\
\hline$([0.3,0.4],[0.5,0.6])$ & MP & Medium Poor \\
\hline$([0.2,0.2],[0.7,0.7])$ & P & Poor \\
\hline$([0.0,0.1],[0.8,0.9])$ & VP & Very Poor \\
\hline
\end{tabular}




\section{Tab. 3: Decision made by Expert Opinions}

\begin{tabular}{|c|c|c|c|c|c|c|c|}
\hline Criterion & Type & Weights & ES1 & ES2 & ES3 & ES4 & ES5 \\
\hline $\mathrm{C} 1$ & positive & 0.030 & VP & $\mathrm{P}$ & $\mathrm{F}$ & MG & MG \\
\hline $\mathrm{C} 2$ & positive & 0.035 & MP & $\mathrm{F}$ & MG & G & MG \\
\hline C3 & positive & 0.030 & $\mathrm{~F}$ & $\mathrm{P}$ & MP & $\mathrm{F}$ & $\mathrm{P}$ \\
\hline $\mathrm{C} 4$ & positive & 0.022 & MP & VP & $P$ & $F$ & MP \\
\hline C5 & positive & 0.022 & MG & VP & $\mathrm{P}$ & $\mathrm{F}$ & MP \\
\hline C6 & positive & 0.022 & $\mathrm{~F}$ & VP & $P$ & $G$ & VP \\
\hline C7 & positive & 0.035 & $G$ & VG & MG & G & $G$ \\
\hline $\mathrm{C} 8$ & positive & 0.035 & MG & $G$ & MG & VG & MG \\
\hline C9 & positive & 0.030 & VG & MG & $\mathrm{F}$ & VP & MG \\
\hline C10 & positive & 0.022 & $\mathrm{~F}$ & MP & $\mathrm{F}$ & $\mathrm{F}$ & MG \\
\hline C11 & positive & 0.009 & $\mathrm{~F}$ & $\mathrm{~V}$ & $P$ & $\mathrm{~F}$ & MG \\
\hline $\mathrm{C} 12$ & positive & 0.043 & VG & VG & MG & G & MG \\
\hline C13 & positive & 0.035 & $\mathrm{~F}$ & MG & $\mathrm{F}$ & MG & VG \\
\hline C14 & positive & 0.009 & G & VP & MP & $P$ & VP \\
\hline C15 & positive & 0.022 & MP & VP & $P$ & MP & VP \\
\hline C16 & positive & 0.030 & VP & VP & $\mathrm{F}$ & $\mathrm{F}$ & VP \\
\hline C17 & positive & 0.030 & $F$ & $P$ & $\mathrm{~F}$ & MG & VP \\
\hline C18 & positive & 0.035 & MG & VG & MG & MG & MG \\
\hline C19 & positive & 0.043 & VG & VG & MG & VG & MG \\
\hline $\mathrm{C} 20$ & positive & 0.035 & VP & MP & $\mathrm{F}$ & VP & $P$ \\
\hline $\mathrm{C} 21$ & positive & 0.009 & $P$ & VP & $\mathrm{F}$ & MP & $\mathrm{F}$ \\
\hline $\mathrm{C} 22$ & positive & 0.022 & VP & $\mathrm{F}$ & $\mathrm{F}$ & $\mathrm{P}$ & VP \\
\hline $\mathrm{C} 23$ & positive & 0.022 & VP & $\mathrm{F}$ & $\mathrm{F}$ & MG & $P$ \\
\hline $\mathrm{C} 24$ & positive & 0.035 & MG & $\mathrm{F}$ & $\mathrm{F}$ & VG & $\mathrm{F}$ \\
\hline $\mathrm{C} 25$ & positive & 0.035 & VG & MG & G & G & $\mathrm{G}$ \\
\hline C26 & positive & 0.043 & VG & $G$ & MG & $G$ & MG \\
\hline $\mathrm{C} 27$ & positive & 0.030 & VG & G & VG & VG & G \\
\hline $\mathrm{C} 28$ & positive & 0.022 & $\mathrm{~F}$ & MG & $\mathrm{F}$ & $\mathrm{F}$ & VG \\
\hline $\mathrm{C} 29$ & positive & 0.022 & VP & $\mathrm{P}$ & $\mathrm{F}$ & MG & $\mathrm{F}$ \\
\hline $\mathrm{C} 30$ & positive & 0.035 & VP & MG & MP & $\mathrm{P}$ & $\mathrm{F}$ \\
\hline C31 & positive & 0.035 & VP & $\mathrm{P}$ & $\mathrm{F}$ & VP & $\mathrm{F}$ \\
\hline $\mathrm{C} 32$ & positive & 0.035 & MG & $\mathrm{P}$ & MP & $\mathrm{F}$ & VG \\
\hline C33 & positive & 0.043 & $\mathrm{~F}$ & $\mathrm{~F}$ & $P$ & MG & $\mathrm{F}$ \\
\hline C34 & positive & 0.043 & VG & $P$ & $\mathrm{~F}$ & $\mathrm{~F}$ & MG \\
\hline
\end{tabular}




\section{Tab. 4: Normalized Weighted Decision Matrix}

\begin{tabular}{|c|c|c|c|c|c|}
\hline & E1 & E2 & E3 & E4 & E5 \\
\hline $\mathrm{C} 1$ & $([0,0.003],[0.993,0.997])$ & $([0.007,0.007],[0.989,0.989])$ & $([0.021,0.021],[0.973,0.979])$ & $([0.027,0.036],[0.952,0.964])$ & $([0.027,0.036],[0.952,0.964])$ \\
\hline $\mathrm{C} 2$ & $([0.012,0.018],[0.976,0.982])$ & $([0.024,0.024],[0.969,0.976])$ & $([0.031,0.041],[0.946,0.959])$ & $([0.054,0.054],[0.923,0.923])$ & $([0.031,0.041],[0.946,0.959])$ \\
\hline $\mathrm{C} 3$ & $([0.021,0.021],[0.973,0.979])$ & $([0.007,0.007],[0.989,0.989])$ & $([0.011,0.015],[0.979,0.985])$ & $([0.021,0.021],[0.973,0.979])$ & $([0.007,0.007],[0.989,0.989])$ \\
\hline $\mathrm{C} 4$ & $([0.008,0.011],[0.985,0.989])$ & $([0,0.002],[0.995,0.998])$ & $([0.005,0.005],[0.992,0.992])$ & $([0.015,0.015],[0.980,0.985])$ & $([0.008,0.011],[0.985,0.989])$ \\
\hline $\mathrm{C} 5$ & $([0.020,0.026],[0.966,0.974])$ & $([0,0.002],[0.995,0.998])$ & $([0.005,0.005],[0.992,0.992])$ & $([0.015,0.015],[0.980,0.985])$ & $([0.008,0.011],[0.985,0.989])$ \\
\hline $\mathrm{C} 6$ & $([0.015,0.015],[0.980,0.985])$ & $([0,0.002],[0.995,0.998])$ & $([0.005,0.005],[0.992,0.992])$ & $([0.034,0.034],[0.951,0.951])$ & $([0,0.002],[0.995,0.998])$ \\
\hline $\mathrm{C} 7$ & $([0.054,0.054],[0.923,0.923])$ & $([0.077,1],[0,0])$ & $([0.031,0.041],[0.946,0.959])$ & $([0.054,0.054],[0.923,0.923])$ & $([0.054,0.054],[0.923,0.923])$ \\
\hline $\mathrm{C} 8$ & $([0.031,0.041],[0.946,0.959])$ & $([0.054,0.054],[0.923,0.923])$ & $([0.031,0.041],[0.946,0.959])$ & $([0.077,1],[0,0])$ & $([0.031,0.041],[0.946,0.959])$ \\
\hline $\mathrm{Cg}$ & $([0.067,1],[0,0])$ & $([0.027,0.036],[0.952,0.964])$ & $([0.021,0.021],[0.973,0.979])$ & $([0,0.003],[0.993,0.997])$ & $([0.027,0.036],[0.952,0.964])$ \\
\hline $\mathrm{C} 10$ & $([0.015,0.015],[0.980,0.985])$ & $([0.008,0.011],[0.985,0.989])$ & $([0.015,0.015],[0.980,0.985])$ & $([0.015,0.015],[0.980,0.985])$ & $([0.020,0.026],[0.966,0.974])$ \\
\hline $\mathrm{C} 11$ & $([0.006,0.006],[0.992,0.994])$ & $([0,0],[0,0])$ & $([0.002,0.002],[0.997,0.997])$ & $([0.006,0.006],[0.992,0.994])$ & $([0.008,0.010],[0.986,0.990])$ \\
\hline $\mathrm{C} 12$ & $([0.095,1],[0,0])$ & $([0.095,1],[0,0])$ & $([0.039,0.051],[0.933,0.949])$ & $([0.067,0.067],[0.905,0.905])$ & $([0.039,0.051],[0.933,0.949])$ \\
\hline $\mathrm{C} 13$ & $([0.024,0.024],[0.969,0.976])$ & $([0.031,0.041],[0.946,0.959])$ & $([0.024,0.024],[0.969,0.976])$ & $([0.031,0.041],[0.946,0.959])$ & $([0.077,1],[0,0])$ \\
\hline $\mathrm{C} 14$ & $([0.014,0.014],[0.980,0.980])$ & $([0,0.001],[0.998,0.999])$ & $([0.003,0.004],[0.994,0.996])$ & $([0.002,0.002],[0.997,0.997])$ & $([0,0.001],[0.998,0.999])$ \\
\hline $\mathrm{C} 15$ & $([0.008,0.011],[0.985,0.989])$ & $([0,0.002],[0.995,0.998])$ & $([0.005,0.005],[0.992,0.992])$ & $([0.008,0.011],[0.985,0.989])$ & $([0,0.002],[0.995,0.998])$ \\
\hline $\mathrm{C} 16$ & $([0,0.003],[0.993,0.997])$ & $([0,0.003],[0.993,0.997])$ & $([0.021,0.021],[0.973,0.979])$ & $([0.021,0.021],[0.973,0.979])$ & $([0,0.003],[0.993,0.997])$ \\
\hline $\mathrm{C} 17$ & $([0.021,0.021],[0.973,0.979])$ & $([0.007,0.007],[0.989,0.989])$ & $([0.021,0.021],[0.973,0.979])$ & $([0.027,0.036],[0.952,0.964])$ & $([0,0.003],[0.993,0.997])$ \\
\hline $\mathrm{C} 18$ & $([0.031,0.041],[0.946,0.959])$ & $([0.077,1],[0,0])$ & $([0.031,0.041],[0.946,0.959])$ & $([0.031,0.041],[0.946,0.959])$ & $([0.031,0.041],[0.946,0.959])$ \\
\hline C19 & $([0.095,1],[0,0])$ & $([0.095,1],[0,0])$ & $([0.039,0.051],[0.933,0.949])$ & $([0.095,1],[0,0])$ & $([0.039,0.051],[0.933,0.949])$ \\
\hline $\mathrm{C} 20$ & $([0,0.004],[0.992,0.996])$ & $([0.012,0.018],[0.976,0.982])$ & $([0.024,0.024],[0.969,0.976])$ & $([0,0.004],[0.992,0.996])$ & $([0.008,0.008],[0.988,0.988])$ \\
\hline $\mathrm{C} 21$ & $([0.002,0.002],[0.997,0.997])$ & $([0,0.001],[0.998,0.999])$ & $([0.006,0.006],[0.992,0.994])$ & $([0.003,0.004],[0.994,0.996])$ & $([0.006,0.006],[0.992,0.994])$ \\
\hline $\mathrm{C} 22$ & $([0,0.002],[0.995,0.998])$ & $([0.015,0.015],[0.980,0.985])$ & $([0.015,0.015],[0.980,0.985])$ & $([0.005,0.005],[0.992,0.992])$ & $([0,0.002],[0.995,0.998])$ \\
\hline $\mathrm{C} 23$ & $([0,0.002],[0.995,0.998])$ & $([0.015,0.015],[0.980,0.985])$ & $([0.015,0.015],[0.980,0.985])$ & $([0.020,0.026],[0.966,0.974])$ & $([0.005,0.005],[0.992,0.992])$ \\
\hline $\mathrm{C} 24$ & $([0.031,0.041],[0.946,0.959])$ & $([0.024,0.024],[0.969,0.976])$ & $([0.024,0.024],[0.969,0.976])$ & $([0.077,1],[0,0])$ & $([0.024,0.024],[0.969,0.976])$ \\
\hline $\mathrm{C} 25$ & $([0.077,1],[0,0])$ & $([0.031,0.041],[0.946,0.959])$ & $([0.054,0.054],[0.923,0.923])$ & $([0.054,0.054],[0.923,0.923])$ & $([0.054,0.054],[0.923,0.923])$ \\
\hline $\mathrm{C} 26$ & $([0.095,1],[0,0])$ & $([0.067,0.067],[0.905,0.905])$ & $([0.039,0.051],[0.933,0.949])$ & $([0.067,0.067],[0.905,0.905])$ & $([0.039,0.051],[0.933,0.949])$ \\
\hline $\mathrm{C} 27$ & $([0.067,1],[0,0])$ & $([0.048,0.048],[0.933,0.933])$ & $([0.067,1],[0,0])$ & $([0.067,1],[0,0])$ & $([0.048,0.048],[0.933,0.933])$ \\
\hline $\mathrm{C} 28$ & $([0.015,0.015],[0.980,0.985])$ & $([0.020,0.026],[0.966,0.974])$ & $([0.015,0.015],[0.980,0.985])$ & $([0.015,0.015],[0.980,0.985])$ & $([0.049,1],[0,0])$ \\
\hline $\mathrm{C} 29$ & $([0,0.002],[0.995,0.998])$ & $([0.005,0.005],[0.992,0.992])$ & $([0.015,0.015],[0.980,0.985])$ & $([0.020,0.026],[0.966,0.974])$ & $([0.015,0.015],[0.980,0.985])$ \\
\hline $\mathrm{C} 30$ & $([0,0.004],[0.992,0.996])$ & $([0.031,0.041],[0.946,0.959])$ & $([0.012,0.018],[0.976,0.982])$ & $([0.008,0.008],[0.988,0.988])$ & $([0.024,0.024],[0.969,0.976])$ \\
\hline C31 & $([0,0.004],[0.992,0.996])$ & $([0.008,0.008],[0.988,0.988])$ & $([0.024,0.024],[0.969,0.976])$ & $([0,0.004],[0.992,0.996])$ & $([0.024,0.024],[0.969,0.976])$ \\
\hline $\mathrm{C} 32$ & $([0.031,0.041],[0.946,0.959])$ & $([0.008,0.008],[0.988,0.988])$ & $([0.012,0.018],[0.976,0.982])$ & $([0.024,0.024],[0.969,0.976])$ & $([0.077,1],[0,0])$ \\
\hline $\mathrm{C} 33$ & $([0.030,0.030],[0.961,0.970])$ & $([0.030,0.030],[0.961,0.970])$ & $([0.010,0.010],[0.985,0.985])$ & $([0.039,0.051],[0.933,0.949])$ & $([0.030,0.030],[0.961,0.970])$ \\
\hline $\mathrm{C} 34$ & $([0.095,1],[0,0])$ & $([0.010,0.010],[0.985,0.985])$ & $([0.030,0.030],[0.961,0.970])$ & $([0.030,0.030],[0.961,0.970])$ & $([0.039,0.051],[0.933,0.949])$ \\
\hline
\end{tabular}


Tab. 5: Euclidean and Hamming distances of alternatives from negative-ideal solution

\begin{tabular}{l|c|c}
\multicolumn{1}{c|}{ alternatives } & E & T \\
\hline ES1 & 0.1569 & 0.3770 \\
\hline ES2 & 0.1070 & 0.3072 \\
\hline ES3 & 0.0293 & 0.1400 \\
\hline ES4 & 0.0998 & 0.2839 \\
\hline ES5 & 0.0753 & 0.2533 \\
\hline
\end{tabular}

Source: own

\section{Tab. 6: Relative assessment matrix}

\begin{tabular}{l|r|r|r|r|r} 
& \multicolumn{1}{|c|}{ ES1 } & \multicolumn{1}{c|}{ ES2 } & \multicolumn{1}{c|}{ ES3 } & \multicolumn{1}{c}{ ES4 } & \multicolumn{1}{c}{ ES5 } \\
\hline ES1 & 0 & 0.1197 & 0.3645 & 0.1501 & 0.2053 \\
\hline ES2 & -0.1197 & 0 & 0.2448 & 0.0072 & 0.0856 \\
\hline ES3 & -0.3645 & -0.2448 & 0 & -0.2144 & -0.1592 \\
\hline ES4 & -0.1501 & -0.0072 & 0.2144 & 0 & 0.0552 \\
\hline ES5 & -0.2053 & -0.0856 & 0.1592 & -0.0552 & 0 \\
\hline
\end{tabular}

Source: own

Tab. 7: Assessment scores and final rankings

\begin{tabular}{l|c|c}
\multicolumn{1}{c|}{ Alternative } & Assessment Score & Final Ranking \\
\hline ES1 & 0.8397 & 1 \\
\hline ES2 & 0.2178 & 2 \\
\hline ES3 & -0.9829 & 5 \\
\hline ES4 & 0.1123 & 3 \\
\hline ES5 & -0.1869 & 4 \\
\hline
\end{tabular}

Source: own

rank the alternatives through the CODAS-IVIF framework, the maximum and minimum values of each alternative are determined by Equations (13) and (14), and normalized decision matrix is calculated using Equation (28). According to Step 3 in the framework, then, Equation (29) is to assign a weighting of relative importance to each criterion and to calculate the weighted normalized decision matrix (Tab. 4).

In the next step, the negative-ideal solution is calculated using Equation (30) for each criterion, and then Euclidean distance $(E)$ and Hamming distance (T) values for each alternative are calculated by using Equations
(31) and (32), respectively. Tab. 5 represents the results.

Based on the logic of the CODAS-IVIF method, the relative assessment matrix should be determined by Equations (33) and (34). This matrix is shown in Tab. 6.

In the final step, the assessment score of each alternative are calculated using Equation (35) and Tab. 6, and then ranked accordingly. Assuming $\theta=0.02$ for the calculations, the results are presented in Tab. 7 .

As found, the ES1 can be selected as the best alternative for business intelligence system. The analysis results represent its 
Tab. 8: Ranking the alternatives applying different methods

\begin{tabular}{l|c|c|c|c}
\multicolumn{1}{c|}{ Alternative } & CODAS-IVIF & TODIM-IVIF & COPRAS-IVIF & MABAC-IVIF \\
\hline ES1 & 1 & 2 & 1 & 2 \\
\hline ES2 & 2 & 5 & 2 & 4 \\
\hline ES3 & 5 & 4 & 3 & 5 \\
\hline ES4 & 3 & 1 & 4 & 1 \\
\hline ES5 & 4 & 3 & 5 & 3 \\
\hline
\end{tabular}

Source: own

\section{Tab. 9: Ranking similarity for four ranking methods}

\begin{tabular}{l|c|c|c|c} 
& CODAS-IVIF & TODIM-IVIF & COPRAS-IVIF & MABAC-IVIF \\
\hline CODAS-IVIF & $1(100 \%)$ & $0.2(0 \%)$ & $0.7(40 \%)$ & $0.5(20 \%)$ \\
\hline TODIM-IVIF & $0.2(0 \%)$ & $1(100 \%)$ & $-0.2(0 \%)$ & $0.9(60 \%)$ \\
\hline COPRAS-IVIF & $0.7(40 \%)$ & $-0.2(0 \%)$ & $1(100 \%)$ & $-0.1(0 \%)$ \\
\hline MABAC-IVIF & $0.5(20 \%)$ & $0.9(60 \%)$ & $-0.1(0 \%)$ & $1(100 \%)$ \\
\hline
\end{tabular}

Source: own

superior performance in terms of data mining, data warehousing, evolutionary prototyping, reliability and accuracy, although it provides poor efficiency for some criteria in relation to other alternatives under consideration. And, such complexity highlights the need for even more precise methods of multi-criteria decision making.

To evaluate the validity of the results from the extended CODAS-IVIF method, the

\section{Fig. 4: $Z$ values for the four ranking methods}

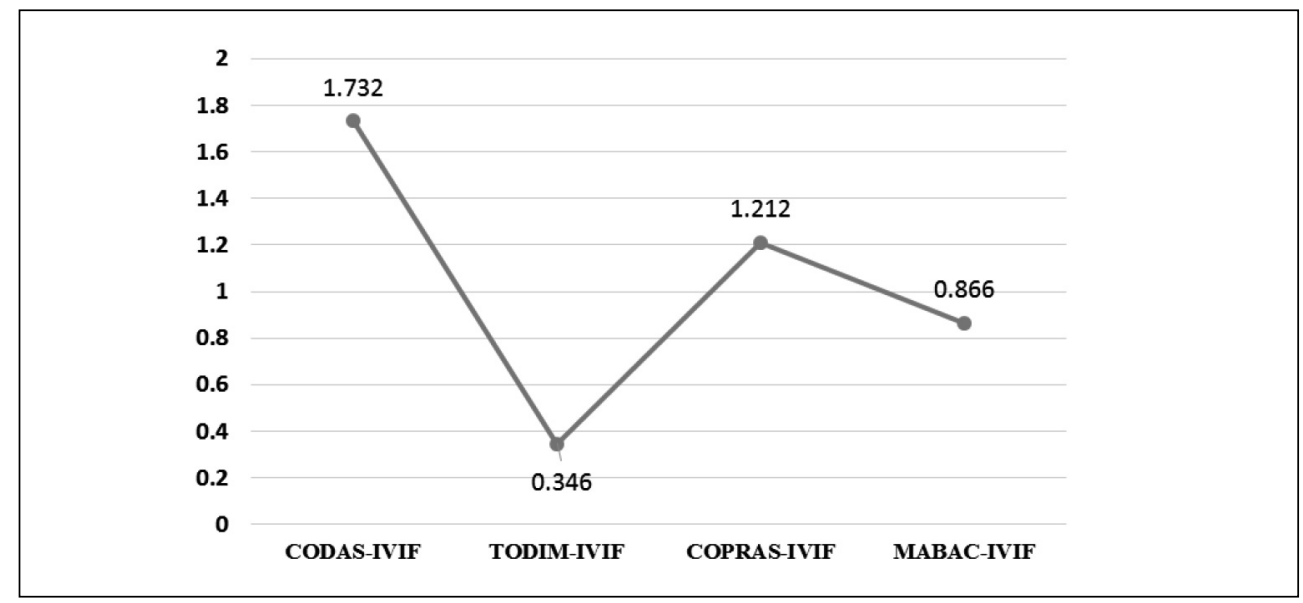


problem is examined by using the TODIM-IVIF (Krohling \& Pacheco, 2014), COPRAS-IVIF (Razavi Hajiagha, Hashemi, \& Zavadskas, 2013) and MABAC-IVIF (Xue, You, Lai, \& Liu, 2016) methods, shown in Tab. 8.

For the comparative analysis, the Spearman's rank correlation coefficient values $\left(r_{s}\right)$ are calculated and shown in Tab. 9.

The values in parentheses represent the correspondence for the ranked alternatives between the CODAS-IVIF method and other different methods. The relative performance of these methods with respect to the ranking of CODAS-IVIF is well visualized using the value of $Z$ as equation 36 :

$$
Z=r_{s} \sqrt{m-1}
$$

Fig. 4 shows a schematic view of $Z$ values.

Based on the values of Spearman correlation coefficient, the ranks provided by the CODASIVIF method seem very similar to the COPRASIVIF method and a $40 \%$ correspondence is observed between these two methods. Also, among other method comparisons, the $Z$ value indicates that the highest performance similarity between the CODAS-IVIF and COPRAS-IVIF methods, followed by the MABAC-IVIF method.

\section{Conclusions}

Business intelligence (BI) is among the fundamental components of information system resources as well as the essential requirements for an organization's success. The growing tendency to use smart devices in enterprise systems has increased the practical necessity of enterprise-level $\mathrm{BI}$ evaluation. The current study applied $\mathrm{BI}$ as the key requirement for enterprise systems. It evaluated 34 criteria derived from the literature review and also 5 alternatives as the levels of $\mathrm{BI}$ through the application of MCDM techniques.

Given uncertainty in real-world decisions and failures in experts' subjective assessments, it seems even more necessary to provide a new accurate approach for the evaluation of business intelligence in enterprise systems, which can deal with uncertain conditions well. Therefore, this study provided a novel approach for $\mathrm{BI}$ evaluation through the extension of a new MADM method, known as CODAS, by using the intuitionistic fuzzy logic with interval values.

As one of the recent multiple attribute decisionmaking (MADM) methods, the CODAS approach was developed by (Kershavarz Ghorabaee,
Zavadskas, Turskis, \&Antucheviciene, 2016). This method relies on the distance from a negativeideal solution, and because of the combination of two Euclidean and Taxicab distances in the assessment process of alternatives, it shows significant performance than other distancebased methods like TOPSIS and VIKOR. Moreover, the interval-valued Intuitionistic fuzzy (IVIF) sets are used to determine membership and non-membership values of elements, which allows more flexibility and increased accuracy under uncertainty. So, the integration of CODAS and IVIF sets can provide a powerful decision tool under conditions of uncertainty.

The results revealed that the most importantt assessment criteria defined by expert panels included visual graph display, dashboard and recommender, capable of data storage, meeting stakeholder needs, and the possibility for detailed realistic analysis. When the values of criterion weights determined, the CODAS-IVIF method proposed here was employed to evaluate and rank the enterprise systems under study.

Moreover, in order to measure the validity of the proposed framework, the research problem was analysed by using three different methods; namely, TODIM-IVIF, COPRAS-IVIF, and MABAC-IVIF. Compared to the CODASIVIF method, the results showed a significant similarity between the extended CODAS-IVIF and COPRAS-IVIF methods for the ranked alternatives. For these two methods, the Spearman's correlation coefficient was 0.7 and the correspondence was present in $40 \%$ of the results. Also, the Spearman's correlation coefficient of 0.5 between the CODAS-IVIF and MABAC-IVIF methods revealed that a relatively acceptable correlation existed.

The framework provided here can be utilized by organizations to make sound decisions regarding their levels of business intelligence. Further studies are recommended to use different decision-making approaches and methods under uncertainty, so it would be possible to compare the current results with the findings from other major research studies.

\section{References}

Alter, S. (2004). Work system view of DSS in its fourth decade. Decision Support, 38, 319-327. https://doi.org/10.1016/j.dss.2003.04.001.

Aruldoss, M., Lakshmi Travis, M., \& Prasanna Venkatesan, V. (2014). A survey 
on recent research in business intelligence. Journal of Enterprise Information Management, 27(6), 831-866. https://doi.org/10.1108/JEIM06-2013-0029.

Atanassov, K., \& Gargov, G. (1989). Interval valued intuitionistic fuzzy sets. Fuzzy sets and systems, 31(3), 343-349. https://doi. org/10.1016/0165-0114(89)90205-4.

Boran, F. E., Genç, S., Kurt, M., \& Akay, D. (2009). A multi-criteria intuitionistic fuzzy groupdecision making for supplier selection with TOPSIS method. Expert Systems with Applications, 36(8), 11363-11368. https://doi. org/10.1016/j.eswa.2009.03.039.

Bose, R. (2009). Advanced analytics: opportunities and challenges. Industrial Management \& Data Systems, 109(2), 155-172. https://doi.org/10.1108/02635570910930073.

Chang, V. (2014). The business intelligence as a service in the cloud. Future Generation Computer Systems, 37, 512-534. https://doi. org/10.1016/j.future.2013.12.028.

Chen, H., Chiang, R. H., \& Storey, V. C. (2012). Business intelligence and analytics: From big data to big impact. MIS quarterly, 36(4), 1165-1188.

Doll, W. J., \& Torzadeh, G. (1988). The measurement of end-user satisfaction. MIS Quarterly, 12(2), 259-274. https://doi.org/10.2307/248851.

Duan, L., \& Da Xu, L. (2012). Business intelligence for enterprise systems: a survey. IEEE Transactions on Industrial Informatics, 8(3), 679-687. https://doi.org/10.1109/TII.2012.2188804.

Gangadharan, G. R., \& Swami, S. N. (2004). Business intelligence systems: design and implementation strategies. In 26th International Conference In Information Technology Interfaces (pp. 139-144). IEEE.

Garg, H. (2017). Novel intuitionistic fuzzy decision making method based on an improved operation laws and its application. Engineering Applications of Artificial Intelligence, 60, 164-174. https://doi.org/10.1016/j.engappai.2017.02.008.

Ghazanfari, M., Jafari, M., \& Rouhani, S. (2011). A tool to evaluate the business intelligence of enterprise systems. Scientia Iranica, 18(6), 1579-1590. https://doi. org/10.1016/j.scient.2011.11.011.

Holsapple, C., Lee-Post, A., \& Pakath, R. (2014). A unified foundation for business analytics. Decision Support Systems, 64, 130141. https://doi.org/10.1016/j.dss.2014.05.013.

Işık, Ö., Jones, M. C., \& Sidorova, A. (2013). Business intelligence success: The roles of
BI capabilities and decision environments. Information \& Management, 50(1), 13-23. https://doi.org/10.1016/j.im.2012.12.001.

Kershavarz Ghorabaee, M., Amiri, M., Zavadskas, E. K., Hooshmand, R., \& Antuchevičienè, J. (2017). Fuzzy extension of the CODAS method for multi-criteria market segment evaluation. Journal of Business Economics and Management, 18(1), 1-19. https://doi.org/10.3846/16111699.2016.1278559.

Kershavarz Ghorabaee, M., Zavadskas, E. K., Turskis, Z., \& Antucheviciene, J. (2016). A new combinative distance-based assessment (CODAS) method for multi-criteria decisionmaking. Economic Computation \& Economic Cybernetics Studies \& Research, 50(3).

Krohling, R. A., \& Pacheco, A. G. (2014). Interval-valued intuitionistic fuzzy TODIM. Procedia Computer Science, 31, 236-244. https://doi.org/10.1016/j.procs.2014.05.265.

Lin, Y. H., Tsai, K. M., Shiang, W. J., Kuo, T. C., \& Tsai, C. H. (2009). Research on using ANP to establish a performance assessment model for business intelligence systems. Expert Systems with Applications, 36(2), 4135-4146. https://doi.org/10.1016/j.eswa.2008.03.004.

Liu, D. (2010). Extension principles for interval-valued intuitionistic fuzzy sets andalgebraic operations. Fuzzy Optimization and Decision Making, 10(1), 45-58. https://doi. org/10.1007/s10700-010-9095-9.

Liu, W. J., Lin, Z. Z., Wen, F. S., \& Ledwich, G. (2012). Intuitionistic fuzzy Choquet integral operator-based approach for black-start decision making. Generation, Transmission \& Distribution, 6(5), 378-386. https://dx.doi. org/10.1049/iet-gtd.2011.0609.

Lönnqvist, A., \& Pirttimäki, V. (2006). The measurement of business intelligence. Information systems management, 23(1), 3240. https://dx.doi.org/10.1201/1078.10580530/ 45769.23.1.20061201/91770.4.

Massa, S., \& Testa, S. (2005). Data warehouse-in-practice: exploring the function of expectations in organizational outcomes. Information \& Management, 42(5), 709-718. https://doi.org/10.1016/j.im.2004.06.002.

Olszak, C. M., \& Ziemba, E. (2007). Approach to building and implementing business intelligence systems. Interdisciplinary Journal of Information, Knowledge, and Management, 2(1), 135-148. https://doi.org/10.28945/105.

Popovič, A., Hackney, R., Coelho, P. S., \& Jaklič, J. (2012). Towards business intelligence 
systems success: Effects of maturity and culture on analytical decision making. Decision Support Systems, 54(1), 729-739. https://doi. org/10.1016/j.dss.2012.08.017.

Power, D. J. (2008). Understanding datadriven decision support systems. Information Systems Management, 25(2), 149-154. https:// doi.org/10.1080/10580530801941124.

Razavi Hajiagha, S. H., Hashemi, S. S., \& Zavadskas, E. K. (2013). A complex proportional assessment method for group decision making in an interval-valued intuitionistic fuzzy environment. Technological and Economic Development of Economy, 19(1), 22-37. https://dx.doi.org/10.3846/20294913.2012.762953.

Rouhani, S., Ghazanfari, M., \& Jafari, M. (2012). Evaluation model of business intelligence for enterprise systems using fuzzy TOPSIS. Expert Systems with Applications, 39(3), 3764-3771. https://doi.org/10.1016/j. eswa.2011.09.074.

Rubin, E., \& Rubin, A. (2013). The impact of business intelligence systems on stock return volatility. Information \& Management, 50(2-3), 67-75. https://doi.org/10.1016/j. im.2013.01.002.

Sangari, M. S., \& Razmi, J. (2015). Business intelligence competence, agile capabilities, and agile performance in supply chain: An empirical study. The International Journal of Logistics Management, 26(2), 356-380. https://doi. org/10.1108/IJLM-01-2013-0012.

Tan, B. W., \& Lo, T. W. (1990). Validation of a user satisfaction instrument for office automation success. Information \& Management, 18(4), 203-208. https://doi. org/10.1016/0378-7206(90)90041-F.

Wang, W., \& Liu, X. (2013). The multiattribute decision making method based on interval-valued intuitionistic fuzzy Einstein hybrid weighted geometric operator. Computers \& Mathematics with Applications, 66(10), 1845-1856. https://doi.org/10.1016/j. camwa.2013.07.020.

Xu, Z.-S. (2007). Methods for aggregating interval-valued intuitionistic fuzzy information and their application to decision making. Control and Decision, 22(2), 215-219.

Xue, Y. X., You, J. X., Lai, X. D., \& Liu, H. C. (2016). An interval-valued intuitionistic fuzzy MABAC approach for material selection with incomplete weight information. Applied Soft Computing, 38, 703-713. https://doi. org/10.1016/j.asoc.2015.10.010.
Yan, S. L., Wang, Y., \& Liu, J. C. (2012). Research on the comprehensive evaluation of business intelligence system based on BP neural network. Systems Engineering Procedia, 4, 275-281. https://doi.org/10.1016/j. sepro.2011.11.076.

Yeoh, W., \& Koronios, A. (2010). Critical success factors for business intelligence systems. Journal of computer information systems, 50(3), 23-32. https://dx.doi.org/10.10 80/08874417.2010.11645404.

Zavadskas, E. K., Antucheviciene, J., Hajiagha, S., \& Hashemi, S. (2014). Extension of weighted aggregated sum product assessment with interval-valued intuitionistic fuzzy numbers (WASPAS-IVIF). Applied Soft Computing, 24, 1013-1021. https://doi.org/10.1016/j. asoc.2014.08.031.

Prof. Ing. Jalil Heidary Dahooei, Ph.D. University of Tehran Faculty of Management Department of Management Iran heidaryd@ut.ac.ir

Prof. Edmundas Kazimieras Zavadskas, Ph.D. Vilnius Gediminas Technical University Research Institute of Smart Building Technologies Lithuania edmundas.zavadskas@vgtu.It

Amir Salar Vanaki, MSc. University of Tehran

Faculty of Management Department of Management Iran amirsalarvanaki@ut.ac.ir

Hamid Reza Firoozfar, MSc. University of Tehran Faculty of Management Department of Management Iran hmdfiroozfar@ut.ac.ir

Mehdi Keshavarz-Ghorabaee, Ph.D. Candidate Allameh Tabataba'i University Faculty of Management and Accounting Department of Industrial Management Iran m.keshavarz_gh@yahoo.com 


\title{
Abstract
}

\section{AN EVALUATION MODEL OF BUSINESS INTELLIGENCE FOR ENTERPRISE SYSTEMS WITH NEW EXTENSION OF CODAS (CODAS-IVIF)}

\author{
Jalil Heidary Dahooei, Edmundas Kazimieras Zavadskas, Amir Salar Vanaki, \\ Hamid Reza Firoozfar, Mehdi Keshavarz-Ghorabaee
}

Due to today's dynamic and changing environment and the organization need to decide in emergencies and accurate analysis of the internal and external environment from different aspects, creating a decision support environment is considered as a vital factor for the success of organizations that is achieved using business intelligence. Hence, it is necessary to have enterprise systems at a reasonable level of business intelligence to provide an environment suitable for supporting decision makers through aggregation and analysis of data in their database. Therefore, this study provides a novel assessment framework of BI for enterprise systems, by extending of CODAS method with interval-valued intuitive fuzzy sets. The CODAS is a new method for multiple attribute decision making (MADM) problems. In the proposed model, a number of 34 criteria from the most important $B I$ indexes are identified and, accordingly, five enterprise systems are evaluated through expert discussions. The results reveal that the most important assessment criteria defined by expert panels include visual graph display, dashboard design, capable of data storage, meeting stakeholder needs, and the possibility for detailed realistic analysis. Then, one alternative is defined as the final selection which provides an outstanding performance on the criteria of groupware programs, group decision-making tools, training techniques, data transfer capability, knowledge inference, supporting fuzzy concepts under ambiguity and uncertainty, realtime analytical processing, managing email channels, and achieving stakeholder satisfaction. The results obtained from the extended method are compared with three different ranking techniques. And, the analysis of correlation coefficients confirms similarity between this solution and such methods as COPRAS-IVIF and MABAC-IVIF.

Key Words: Business Intelligence, CODAS, Enterprise System, CODAS- IVIF, MADM.

JEL Classification: C44.

DOI: 10.15240/tul/001/2018-3-011 